\section{UM PARAFUSO A MENOS, UM PARAFUSO A MAIS}

\section{SCREW LOOSE, STUCK SCREW}

http://dx.doi.org/10.11606/issn.2175-3180.v13i25p37-50
Lilian Honda ${ }^{I}$

\section{RESUMO}

Os sofrimentos de ordem psíquica são temas recorrentes na poesia de Adília Lopes, seja num registro marcadamente crítico ou irônico, quando não de pura invectiva, contra profissionais da psiquiatria e da psicanálise, ou na alusão aos psicofármacos, seus efeitos adversos no organismo e a displicência com que são prescritos. Os múltiplos sentidos do jogo envolvendo a conformidade às regras e os sofrimentos psíquicos na poética de Adília Lopes tornaram necessário buscar uma conceitualização mais precisa de "normalidade" e "anormalidade" a partir da reflexão filosófica de Georges Canguilhem, autor de O Normal e o Patológico, na qual são investigados os paradigmas que estruturaram o conhecimento médico-científico e as noções de saúde/doença, normalidade/patologia e anomalia, conceitos que passaram a formar a base da multiplicação de dispositivos reguladores em todas as esferas da vida social.

\section{PALAVRAS-CHAVE}

Poesia portuguesa moderna e contemporânea; Adília Lopes.

\section{ABSTRACT}

Psychological sufferings are recurrent themes in Adilia Lopes' poetry, whether in a markedly critical or ironic, if not pure invective, record against psychiatry and psychoanalysis professionals, or in the allusion to psychotropic drugs, their adverse effects on the organism and carelessness with which they are prescribed. Based on the philosophical reflection found in Georges Canguilhem's The Normal and the Pathological, in which the paradigms that structured medical-scientific knowledge and the notions of health/disease, normality/pathology and anomaly are investigated, concepts that started to form the basis for the multiplication of regulatory devices in all spheres of social life, the multiple meanings of this game involving compliance with the rules and psychic suffering in Adilia Lopes' poetics made it necessary to look for a more precise conceptualization of "normality" and "abnormality".

\section{KEYWORDS}

Modern and contemporary Portuguese poetry; Adília Lopes.

\footnotetext{
I Universidade de São Paulo, São Paulo, Brasil.
} 
Em "A humanidade", publicado no livro Z/S (2016b), Adília Lopes parte de um dito popular para colocar em xeque a autoproclamada racionalidade dos seres humanos, atributo que, longe de ser um dom, surge no poema como uma "avaria" exclusiva da espécie e provocada por um excesso, por um algo que extrapola a medida:

Antigamente dizia-se que um doente mental era uma pessoa com um parafuso a menos. O problema da Humanidade é que tem um parafuso a mais. Na caixa dos pirolitos há ali quelque chose qui cloche, que chocalha. Os outros animais não têm esta coisa a mais, esta avaria. As pessoas, bazófia não lhes fala, autoproclamam-se os animais racionais, é claro que é o contrário, as pessoas são irracionais, são estúpidas. As pessoas são os animais irracionais. A prova disso é que a Humanidade não descansa enquanto não der cabo deste mundo (LOPES, 2016b, p. 91).

Em poucas linhas, a poetisa portuguesa atribui a esse parafuso excedente o ímpeto com que a humanidade se lança à devastação do planeta, ao mesmo tempo em que distancia essa força destruidora daqueles que têm "um parafuso a menos". Assim, a expressão "doente mental" tornase uma classificação no mínimo duvidosa, uma vez que a irracionalidade ou a estupidez das pessoas com "um parafuso a mais" é o que as torna capacitadas para conduzir o incansável trabalho de destruição da Terra.

Questões como essa, que giram em torno das noções de (in)adequação social e (a)normalidade, são inescapáveis no decorrer da leitura da obra de Adília Lopes. As múltiplas vozes que habitam sua poética revelam o desconforto com as regras de conduta e certa falta de aptidão para lidar com padrões de comportamento tidos como socialmente adequados; por vezes, deixam entrever até mesmo descaso em relação à normatividade. $\mathrm{O}$ sujeito poético adiliano expressa aguda consciência da força coercitiva das normas, bem como da crueldade das sanções a que estão submetidos aqueles que recusam essa conformação, não somente pela manifestação de um eu que lida com essas circunstâncias, como também pela reverberação de outras vozes dissonantes: a mulher com olhar de fêmea maligna, a criada com piolhos, a acrobata coxa, o escritor de romances escabrosos, o doente do hospital psiquiátrico, os namorados pobres, entre tantas outras figurações de modos de vida divergentes.

Vinculado ao tópico da normatividade, encontra-se a questão dos sofrimentos psíquicos e da saúde mental, um dos temas recorrentes na poesia adiliana, frequentemente abordado de maneira crítica, sob a chave 
da ironia, quando não tomando a forma da desabrida invectiva aos profissionais da área. "Os psicanalistas são darwinistas" (LOPES, 2016a, p. 81), diz um poema do livro Bandolim, onde ainda se pode ler "consultei uma psicanalista medonha" (LOPES, 2016a, p. 120). De Dobra, que reúne a poesia de Adília Lopes publicada até 2014, pode-se pinçar dois outros exemplos semelhantes: "a Dr. a Manuela Brazette, ela é que é uma porcalhona" (LOPES, 2014, p. 408) e "um psiquiatra é um prostituto" (LOPES, 2014, p. 407). Psiquiatras e psicanalistas não são, porém, os únicos objetos da ciência médica sob escrutínio do sujeito poético. Em seus escritos, há referências a teóricos e pesquisadores da área, a hospitais psiquiátricos portugueses, como Miguel Bombarda e Júlio de Matos, e aos antigos médicos cientistas que lidavam com as chamadas "doenças dos nervos", como o escocês William Cullen, que introduziu a categoria nosológica "neurose" no vocabulário médico no século XVIII. São fartas, ainda, menções aos psicofármacos e aos efeitos adversos que provocam no organismo, assim como à displicência com que são prescritos esses "medicamentos do espírito" (ROUDINESCO, 2000, p. 21). Pegue-se como exemplo o poema "Duas intrujonas", de Bandolim, no qual o sujeito poético equipara a psiquiatra à cabeleireira já a partir do título, igualando-as na displicência com que atendem a paciente-cliente:

Nunca tive pesadelos e nunca tive dores de cabeça. Uma vez uma médica psiquiatra não percebeu nada do que eu lhe disse, não trabalhou, mandou-me tomar Surmontil, um remédio para não ter pesadelos.

Uma vez uma cabeleireira impingiu-me um spray para o cabelo para eu pôr quando estava na praia. Eu nunca ia à praia (LOPES, 2016a, p. 117).

Essa discussão torna-se ainda mais inquietante ao se considerar o jogo autobiográfico que atravessa a obra de Adília Lopes, no qual a tematização reiterada dos distúrbios mentais cruza-se com declarações nas quais a poeta torna pública sua doença psíquica, como nesses trechos extraídos de entrevistas, o primeiro deles para uma revista literária: “É claro que o poeta é sempre o idiota da família, o maluquinho" (DIOGO; SILVESTRE, 2001, p. 22). Ou um segundo trecho, retirado de um jornal diário de Lisboa: "Eu vivo de uma maneira sofrida actualmente porque tenho uma doença psíquica, posso vir a ter dificuldades de dinheiro e o mundo não está cor-de-rosa" (LOPES, 2008, p. 109). Essas declarações encontram-se espelhadas em poemas, contendo até mesmo 
correspondências lexicais, como nos versos: "Adília / a idiota / da família" (LOPES, 2014, p. 636), "Tenho uma doença mental / [...] Meus miolos estão à mostra como a mioleira da vaca no balcão de talho" (LOPES, 2014, p. 419) e "Tomo Risperidona. A Risperidona é um remédio ríspido. Torna-me gorda e lenta" (LOPES, 2014, p. 647).

O sentimento de inadequação social que atravessa a poesia de Adília Lopes pressupõe o seu oposto, a conformação às normas. Pensar a normatividade e a normalização torna necessário pensar na progressiva transformação semântica que deu origem à ideia de "normal" como aquilo que é usual, comum, adequado ou aceitável, assim como a noção assumida no âmbito da ciência médica, que é "sem defeitos ou problemas físicos ou mentais". Esta segunda acepção situa qualquer desvio anatômico ou fisiológico, na categoria da anormalidade, fazendo da normalidade dos corpos, dos órgãos e dos processos fisiológicos ou psíquicos a negação da anormalidade, da doença e da anomalia.

Esses dois significados, tão distintos quanto são usuais, obrigam a um questionamento: de que (a)normalidade está falando o sujeito poético adiliano? Algo ou alguém é considerado anormal em relação a quê? E como se opera essa questão epistemológica subjacente aos versos? O ponto de partida será o poema sem título e não datado, publicado por Adília Lopes originalmente em O peixe na água, de 1993:

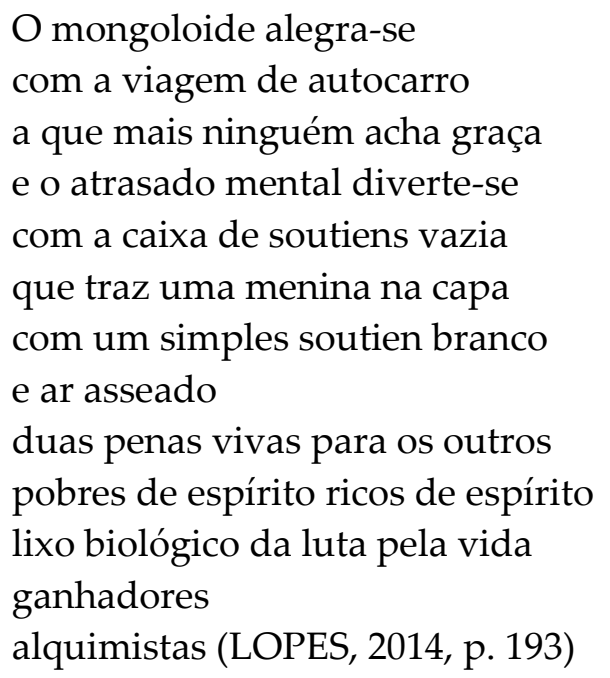

O transporte coletivo é o espaço racional, utilitário e planificado - e, portanto, moderno - em que irrompe o incômodo da coexistência com o "anormal", personificado por duas pessoas com deficiência intelectual, denominadas cruamente como "mongoloide", "atrasado mental" e "penas 
vivas", termos tão pejorativos quanto antigos. Essa circunstância presentifica no espaço contemporâneo do ônibus a história do conceito de deficiência mental, bem como do tratamento dispensado aos deficientes. Os dois primeiros termos derivam do vocabulário médico antigo e ainda são utilizados na linguagem popular, frequentemente como ofensa. $\mathrm{O}$ terceiro, "penas vivas", alude ao entrecruzamento da teologia moral religiosa, que estabelece a pena como um castigo expiatório do pecado, e a ordem jurídico-penal secular, construída sobre o mesmo modelo, na forma de crime, seguido de condenação e punição para remissão do delito.

Nos tempos pré-científicos, a doutrina cristã associou a prédica da caridade à resolução da Igreja Católica de reconhecer a existência de alma nos deficientes. $\mathrm{O}$ resultado foi o acolhimento das pessoas deficientes em conventos e asilos que lhes garantiam abrigo e alimentação; simultaneamente, a condição de cristãos os tornava moralmente culpados tanto por condutas inadequadas quanto por sua própria deficiência. Ao denominá-los "penas vivas", passam a figurar no poema como corporificação do mal e castigo de Deus a si mesmos (cf. PESSOTTI, 1993, p. 11-12). Não só: representam também uma associação de comiseração, aflição, desgosto e castigo "para os outros", como aparece no nono verso. Ressalte-se que o verso "duas penas vivas para os outros" exclui tanto aqueles de quem se fala, como também do eu que fala, sinalizando a aproximação do sujeito poético às duas pessoas com deficiência.

Nesse transcurso poético, há um salto histórico e epistemológico dos tempos pré-científicos à era da ciência, que deu origem à prerrogativa do discurso racional e, no século XVIII, à medicina moderna. No processo, a ideia de personificação da malignidade transformou-se em erro inerente ao organismo, em patologia. "Mongoloide" é uma denominação médica arcaica para pessoas com Síndrome de Down, descrita por John Langdon Down em sua obra Observations on Ethnic Classification of Idiots, de 1866. O médico britânico criou a denominação "mongolismo" pela suposta associação das características fisionômicas das pessoas da etnia mongol com as dos pacientes observados (cf. PESSOTTI, 1993, p. 142), escolha que sinaliza sua adesão às teorias de degeneração da raça ou de involução da espécie que, por sua vez, associa a ideia de inferioridade aos deficientes mentais. Tratados e estudos da mesma época têm em comum a busca de características orgânicas ou funcionais de pacientes com a finalidade de estabelecer uma classificação das deficiências intelectuais em tipos e graus. 
Entre essas inúmeras categorias nosológicas relativas ao "atraso mental" também estariam "cretinos, idiotas, cretinoides, imbecis e retardados" (PESSOTTI, 1993, p. 75-76) e seus tipos e graus. E todos esses termos se equiparam ao conceito de anormal, que tem como uma de suas acepções dicionarizadas "aquele que apresenta desenvolvimento físico, intelectual ou mental defeituoso".

Cristãos incômodos antes, passageiros inconvenientes no presente do poema, o "mongoloide" e o "atrasado mental" permanecem alheios às classificações e aos demais passageiros: um "alegra-se", outro "diverte-se" com a viagem ou com uma caixa de soutien, verbos que fazem um contraponto às denominações depreciativas, revelando um aspecto lúdico que ameniza a cena, assinalando mais uma vez a diferença do olhar lançado pelo sujeito poético a essas duas pessoas. Os deslocamentos de sentido, a intersecção dos tempos e a sobreposição de vozes nesse poema admitem uma reflexão sobre a questão do normal e da anormalidade na poesia de Adília Lopes a partir da obra O Normal e o Patológico, do filósofo e médico Georges Canguilhem, trabalho que se tornou referência na epistemologia histórica contemporânea ao investigar os sentidos que os termos normalidade, anormalidade e anomalia adquiriram no decorrer da história, assim como a ideologização e a naturalização desses conceitos.

Canguilhem discorre sobre a origem inequivocamente técnica do termo "normal", proveniente do latim normālis, que significa "de acordo com a norma". O vocábulo latino norma, por sua vez, é a designação para um instrumento que marca ângulos retos, o esquadro. Com esse sentido técnico, a palavra "normal" entrou no vocabulário francês por meio das reformas sanitária e educacional do final do século XVIII, que instituíram regras para a saúde pública e os hospitais, assim como para a padronização e a expansão do ensino, com a criação das chamadas escolas normais. A adoção do termo, porém, reflete um processo de normalização social iniciado um século antes, com o próprio estabelecimento da norma gramatical culta francesa, a regulamentação dos recursos e procedimentos militares e a padronização dos artigos manufaturados ainda artesanalmente:

Entre 1759, data do aparecimento da palavra normal, e 1834, data do aparecimento da palavra normalizado, uma classe normativa conquistou o poder de identificar a função das normas sociais com o uso que ela própria fazia das normas cujo conteúdo determinava (CANGUILHEM, 2017, p. 195). 
A regulação técnica correspondia às necessidades crescentes da burguesia de obter controle sobre os processos de produção e comércio. Gradativamente, portanto, a normatização passou a transpor as esferas militar, educacional e de saúde, abrangendo as áreas industrial, comercial, econômica, cultural e política. Espelhando o sistema social que se consolidava, assim como sua hierarquia de valores, o termo "normal" deixou de ter apenas um sentido de conformação técnica, assumindo a definição de "usual, comum; natural", assim como a designação de um qualificativo para a pessoa "cujo comportamento é considerado aceitável e comum". Desse modo, a normatização passou a se manifestar como a criação incessante de imperativos para o fazer, para o viver e para o vivente. Toma-se a norma, seja ela externa ou interna ao ser, ao objeto ou ao fato, como referência a outros seres, objetos ou fatos, tornando o normal simultaneamente a exibição da norma, porque a indica, e a extensão dela, porque a multiplica (cf. CANGUILHEM, 2017, p.188).

$\mathrm{Na}$ análise da poética de Adília Lopes, a diferença entre a normalização e a normatividade vital estabelecida por Canguilhem revelou-se produtiva. O filósofo define a normalização como uma disposição regulativa inerente à modernidade, ainda em pleno vigor no modelo biomédico adotado pela medicina e pelas demais áreas relacionadas ou complementares à saúde. Essa operação reguladora determina previamente parâmetros e medidas fixos aos quais o corpo saudável deve corresponder, estabelecendo ações curativas ou corretivas para que o corpo retorne à "normalidade", sendo a ideia de "normal" parametrizada previamente pela ciência médica, não sem significativas ambiguidades, objeções e limitações, segundo Canguilhem. Por sua vez, a normatividade vital caracteriza-se pela plasticidade própria da individualidade biológica, dotada de uma potência criadora de variados (e não necessariamente excludentes entre si) processos de ajustamento imanentes ao organismo. Nesse sentido, o filósofo francês afirma que a anormalidade não pode ser considerada sinônimo de patologia porque o organismo enfrenta a doença não para se conformar a normas, mas sim com a finalidade de restabelecer a continuidade da vida. Um doente procura vencer a doença, no entanto, mais do que isso, também tem a capacidade de instituir novas regras para si, uma nova forma de vida, um outro normal. Já a normalização tem como objeto uma normalidade cujo 
sentido é a criação do seu oposto, por inversão ou violação das regras, do a-normal que antecede qualquer propósito regulativo.

Outra partilha de conceitos que Canguilhem estabelece é a distinção entre "anormalidade" e "anomalia", termos frequentemente tomados como equivalentes. Essa equivalência teria partido de um equívoco etimológico: o Vocabulaire Technique Et Critique de La Philosophie, de André Lalande, esclarece que o vocábulo grego anomalia significa "desigualdade, aspereza" e omalos designa "o que é uniforme, regular, liso". Assim, etimologicamente "anomalia" é an-omalos, aquilo que se mostra desigual, rugoso ou irregular (cf. CANGUILHEM, 2017, p. 84-85). Em outras palavras, "anomalia" indica um fato e refere-se à descrição de um estado ou característica, enquanto "anormal" diz respeito à atribuição de valor segundo determinadas regras. Utilizado originalmente na zoologia com o sentido de "insólito" ou "inusual", o termo "anomalia" foi empregado para apontar um fato biológico da diversidade, uma variação que ocorre na morfologia ou nas funções orgânicas de um indivíduo, que o difere dos demais indivíduos de uma espécie. Ou seja, para a zoologia, a anomalia é expressão da diversidade dos seres, uma norma única, diversa, peculiar e específica de vida. Frequentemente, a anomalia sequer é percebida, porque não representa um impedimento para o funcionamento do organismo, tal como ocorre com a dextrocardia, por exemplo, que é um deslocamento do coração para o lado direito do corpo ou inversão dos compartimentos cardíacos. Assim, não é uma condição que equivalha necessariamente a uma patologia; somente se torna objeto da atenção médica ou científica quando prejudica a ordem vital. No entanto, consolidou-se a equivalência do termo "anomalia" às disformidades graves ou fatais, e estabeleceu-se a percepção negativa das formas de vida anômalas em relação a um modelo idealizado de ser humano.

De volta ao poema de Adília Lopes, ainda que a anomalia cromossômica não impeça o passageiro com Síndrome de Down de viver a seu modo, ele é visto pelos demais como anormal, como uma patologia corporificada. Mais um salto no tempo e é empregado num dos versos a contemporânea expressão "lixo biológico" para qualificar os dois deficientes. Trata-se de uma alusão ao conceito de anomalia morfológica congênita, hipótese já discutida pela medicina do século XIX como causa das idiotias, como derivação da teoria da degeneração, que no começo do século XX passou a ser considerada "erro nato do metabolismo" 
(GARROD apud CANGUILHEM, 2017, p. 223). Os dois passageiros incômodos passam de "penas vivas", encarnação do mal e da punição divina, a portadores de um "vício originário", de "uma herança que o herdeiro não pode recusar, já que a herança e o herdeiro são uma e mesma coisa" (CANGUILHEM, 2017, p. 227). Não há cura para a anormalidade originária, logo, pode-se dizer que essa "hereditariedade é o nome moderno da substância" (CANGUILHEM, 2017, p. 228). A deficiência torna-se, assim, essência do ser, característica análoga ao mal encarnado, seja na concepção moral (pecado), seja no entendimento médico (doença de origem genética).

Outros sentidos podem ser inferidos a partir da expressão "lixo biológico". Nela, costuram-se os significados da palavra "lixo" - tanto a denominação para objeto que se joga fora, ou resto sem utilidade, quanto os sentidos figurados pejorativos, que indicam "pessoa sem qualquer dote moral, físico ou intelectual" e "a camada mais baixa da sociedade; escória, ralé", empregados para subalternizar socialmente os dois passageiros incômodos - ao vocábulo "biológico", relacionando a anomalia morfológica congênita à inferioridade física, corporal, bem como intelectual. Um novo acréscimo de sentido se faz na associação da expressão "lixo biológico" ao jargão empresarial/industrial, no qual a nomenclatura "resíduo biológico" denomina as sobras dos processos produtivos, potenciais contaminantes do meio ambiente. No sentido figurado, essa contaminação pode bem indicar que a presença de duas pessoas com deficiência no espaço racional, utilitário e planificado do ônibus representa uma transgressão à normalização social. Por fim, quando se considera a totalidade do verso "lixo biológico da luta pela vida" evidencia-se a relação de equivalência entre processos vitais do organismo, processos produtivos e processos de organização da sociedade, sobretudo pela associação de "luta pela vida" ao darwinismo social. Esta teoria do século XIX, desenvolvida pelo filósofo e biólogo Herbert Spencer, faz uma equivocada transposição das teses de Charles Darwin sobre os princípios da seleção natural e da evolução das espécies ${ }^{1}$ à organização social. Ainda hoje, são comuns as referências ao mérito dos "mais aptos",

\footnotetext{
${ }^{1}$ Vale lembrar que o "darwinismo social e as teorias dele descendentes entram em contradição, em vários aspectos, com os pontos de vista originais de [Charles] Darwin. Este rejeitava qualquer noção de progresso na transformação de indivíduos e na origem das espécies, e sentia fortes suspeitas das tentativas de se tirarem conclusões de sua obra que fossem aplicáveis à sociedade humana" (OUTHWAITE; BOTTOMORE, 1996, p. 174).
} 
decorrente da naturalização do comportamento competitivo dos indivíduos pela ascensão social ou dos imperativos de crescimento do mercado.

A oposição entre normatividade vital e normalização social se apresenta no poema sob a forma do potencial conflito entre as duas pessoas com deficiência e "os outros" durante uma viagem de ônibus, que é uma figuração metonímica das estruturas de normalização social. A voz do sujeito poético descreve o abalo na normalidade, carregando de tensão esse encontro no autocarro com o emprego dos termos "mongoloide" e "atrasado mental", pejorativos e arcaicos. A alegria e o divertimento da dupla também contrastam com a indiscernibilidade dos demais, homogeneizados pela suspensão temporária das identidades e pela obediência ao papel de passageiros, em conformidade com o uso que se espera de um ônibus, esse "não-lugar" estritamente utilitário, vazio de identidade, relações e memória (cf. AUGÉ, 2016, p. 36). Ao situar os "anormais" em primeiro plano e no centro do acontecimento, o sujeito poético abre espaço para a diversidade de modos de vida excluídos da normalidade e existentes antes da intenção regulatória que determinou o que é ou não normal.

O normal é o efeito obtido pela execução do projeto normativo, é a norma manifestada no fato. Do ponto de vista do fato há, portanto, uma relação de exclusão entre normal e anormal. Essa negação, porém, está subordinada à operação de negação, à correção reclamada pela anormalidade. Não há, portanto, nenhum paradoxo em dizer que o anormal, que logicamente é o segundo, é existencialmente o primeiro (CANGUILHEM, 2017, p. 193).

O conflito latente que se manifesta no poema denuncia a falta de consenso em relação às normas; é um lembrete da permanente contestação à normalização, "sinal de que [...] a sociedade, sede de dissidências contidas ou de antagonismos latentes, está longe de se colocar como um todo" (CANGUILHEM, 2017, p. 205). O sujeito poético atribui justamente a dois excluídos da normalidade a capacidade de ação e de ressignificação de uma atividade rotineira, subvertendo os imperativos de velocidade, controle e eficiência da organização produtiva capitalista. Ao reivindicar e encarnar em si uma outra ordem de espaço e tempo, as "penas vivas" convertem-se em "ganhadores" e "alquimistas", aqueles que têm o poder de converter obediência em potência e de transformar a desumanidade do "não-lugar" em alegria e prazer. 
O modelo biomédico da medicina incorporou saberes como a fisiologia, a patologia, a anatomia patológica e a patogenia, entre outros, no desenvolvimento de uma nova concepção de saúde-doença que se propunha a restaurar cientificamente o estado de normalidade do corpo. A partir do século XIX, esses conhecimentos consolidaram uma teoria de relações entre o normal e o patológico baseada em variações quantitativas dos fenômenos fisiológicos que relacionam as patologias a aumentos e diminuições de índices considerados normais. Essa variação quantitativa, que acarreta uma relação de continuidade entre o normal e o patológico, é a base do chamado "Princípio de Broussais", segundo o qual todas as doenças são variações por excesso ou falta de estímulo dos diversos tecidos do organismo, que o levam a ficar graus abaixo ou acima do que é considerado o estado de normalidade. Extraído da nosologia, esse preceito difundiu-se na medicina por meio de teóricos como o médico e fisiologista Claude Bernard e o filósofo Auguste Comte, que o elevou à categoria de princípio universal, com repercussões em outras áreas do conhecimento, como a filosofia, a sociologia, a política e a literatura (cf. CANGUILHEM, 2017, p. 13). No entanto, nenhum deles apresentou uma definição de qual seria o estado fisiológico normal a partir do qual se estabeleceria uma comparação com um estado patológico. Comte sugeriu que o ponto de partida para a definição dos critérios de normalidade seria a observação dos casos patológicos, o que, paradoxalmente, exigiria um conhecimento prévio do que seria o estado normal; a mesma imprecisão está presente na obra de Bernard, que definiu a condição patológica como "desproporção ou desarmonia" em relação ao normal, ainda que tenha associado dados numéricos a essa interpretação. Harmonia, desarmonia, exagero e atenuação, longe de serem dados mensuráveis, são conceitos qualificativos, valorativos. Até mesmo os termos "excesso" ou "falta", que frequentemente são mencionados como indicativo de patologias, também são atributos qualitativos não manifestamente declarados. Se a finalidade da terapêutica é atingir a normalidade, mas não há critério definido para esse estado, os valores numéricos tidos como corretos e almejáveis para o restabelecimento da saúde equivalem a um ideal de perfeição ao qual os corpos deveriam ser ajustados, ou a um modelo em relação ao qual aquele que é considerado anormal é inferiorizado: “Dizer que a saúde perfeita não existe é apenas dizer que o conceito de saúde não é o de uma existência, mas sim o de uma norma cuja função e cujo valor é relacionar essa norma com a existência a fim de provocar a modificação desta" (CANGUILHEM, 2017, p. 41). 
Para Canguilhem, não há um estado patológico em si; antes, propõe uma inversão na abordagem, tirando o doente da condição de objeto e transformando-o em sujeito, ao afirmar que o indivíduo entra em uma ordem de vida diferente da anterior ao assumir a condição de doente torna-se "outro" na doença - e passa a instituir uma nova norma de vida neste contexto de alteração da normatividade biológica. Lembra o filósofo que "as doenças são novos modos de vida [...]. A doença está na origem da atenção especulativa que a vida dedica à vida, por intermédio do homem" (CANGUILHEM, 2017, p. 61).

Se há diversas lacunas nessa concepção quantitativa e homogeneizante de doença e de saúde, as limitações teóricas serão maiores e inequívocas em relação aos males psíquicos. Não há em relação aos sofrimentos de ordem mental uma ocorrência psíquica elementar e decomponível, como índices mensuráveis em exames médicos de diagnóstico. Logo, uma psicose não pode ser considerada uma extensão da personalidade anterior do doente e um quadro de delírio não deve ser tomado como uma variação para mais ou para menos de um parâmetro qualquer; trata-se, isso sim, de uma mudança da personalidade. A dificuldade de instituir parâmetros de normalidade para o psiquismo ou de estabelecer uma nosografia ou, ainda, de apontar relações orgânicas em transtornos mentais, os tornam ainda mais sujeitos às avaliações morais.

Essa lacuna científica é evidenciada na poesia de Adília Lopes, como no poema abaixo, um exemplo das "ficções autobiográficas" que permeiam sua obra:

Tenho uma doença mental, tenho uma doença de pele. A pele é exterior, o cérebro é interior. Tenho um eczema, tenho uma psicose. Às vezes penso que a pele é interior e que os meus miolos estão à mostra como a mioleira da vaca no balcão do talho (LOPES, 2014, p. 419).

O sujeito poético subverte a ideia essencialista de "verdade profunda", de um núcleo fundamental do ser que precederia as percepções e as experiências. Ao contrário, o poema embaralha as noções de interioridade e exterioridade do corpo. Pensar a pele como "interior" é atribuir a essa "fronteira" corporal um papel na construção da subjetividade: os sentidos e a percepção sensorial, faculdades mais à superfície do corpo, são agentes na constituição do sujeito. Simultaneamente, o poema ironiza a transformação do "doente mental" 
em objeto do conhecimento científico: em "meus miolos estão à mostra [...] no balcão do talho" há uma relação metonímica que se estabelece entre os miolos, a doença mental, ambos dissecados e expostos no balcão do açougue, e a própria subjetividade, que emerge no espaço social como uma outra racionalidade, avessa à hegemonia da razão científica.

A concepção organicista do psiquismo reduziu os fenômenos mentais a um efeito de processos fisiológicos, atribuindo a causa dos transtornos psíquicos a disfunções físico-químicas e, portanto, tornandoos passíveis de serem "curados" por psicofármacos. O resultado foi a expansão da psicofarmacologia e a medicalização dos comportamentos, "fabricando um novo homem, polido e sem humor, esgotado pela evitação de suas paixões, envergonhado por não ser conforme ao ideal que lhe é proposto" (ROUDINESCO, 2000, p. 21). Essa questão surge neste breve poema de Adília Lopes, já mencionado anteriormente: "Tomo Risperidona. A Risperidona é um remédio ríspido. Torna-me gorda e lenta. De corpo e de espírito" (LOPES, 2014, p. 647). O poema sugere que a ideia de normalidade extrapola o âmbito médico-científico, duplicando-se em novas estratégias normalizadoras direcionadas ao corpo e ao comportamento. A administração do psicofármaco não só eliminou a "desconformidade" do sofrimento psíquico, como também exerceu uma ação normalizadora. O medicamento acabou por suprimir também vitalidade, paixões, desejos e angústias, tornando o sujeito poético lento "de corpo e de espírito", o que irá desencadear novas reivindicações normalizadoras, agora na esfera da inadequação social: ser "gorda e lenta" é um desvio das imposições contemporâneas de velocidade, produtividade e beleza.

À custa dos afetos e das singularidades, a normalização impõe um permanente défice entre a condição do sujeito e as exigências que lhe são feitas, acabando por produzir indivíduos cada vez mais parecidos com os "anormais" que se pretendia "exorcizar". É contra essa barbárie normativa que se levanta a voz da poesia de Adília Lopes.

\section{REFERENCIAS}

AUGÉ, Marc. Não-lugares: Introdução a uma antropologia da supermodernidade. Trad. Maria Lúcia Pereira. Campinas: Papirus, 2016.

CANGUILHEM, Georges. O normal e o patológico. Trad. Maria Thereza R. de Carvalho Barrocas. Rio de Janeiro: Forense Universitária, 2017. 
DIOGO, Américo L.; SILVESTRE, Osvaldo M. "Entrevista de Adília Lopes". Inimigo Rumor Revista de Poesia, Rio de Janeiro, n. 10, p. 18-23, 2001.

LOPES, Adília. “Como se faz um poema?". Inimigo Rumor Revista de Poesia, Rio de Janeiro, n. 20, p. 109-110, 2008.

LOPES, Adília. Dobra - Poesia Reunida. Porto: Assírio \& Alvim, 2014.

LOPES, Adília. Bandolim. Porto: Assírio \& Alvim, 2016a.

LOPES, Adília. Z/S. Lisboa: Averno, 2016b.

PESSOTTI, Isaias. Deficiência mental: da superstição à ciência. São Paulo: EDUSP, 1993.

ROUDINESCO, Elizabeth. Por que a psicanálise? Trad. Vera Ribeiro. Rio de Janeiro: Zahar, 2000.

Recebido em 2 de maio de 2021

Aprovado em 26 de setembro de 2021

Lilian Honda

Doutorando em Literatura Portuguesa na Universidade de São Paulo. Mestra em Literatura Portuguesa e Bacharel em Letras-Língua Portuguesa pela mesma Universidade.

Contato: lilian.honda@usp.br

(iD : https://orcid.org/0000-0001-6230-5019

A Revista Desassossego utiliza a Licença Creative Commons Attribution que permite o compartilhamento do trabalho com reconhecimento da autoria e publicação inicial neste veículo - Attribution-NonCommercial-NoDerivates 4.0 International (CC BY-NC-ND 4.0), e reconhece que os Autores têm autorização prévia para assumirem contratos adicionais separadamente para distribuição não-exclusiva de versão dos seus trabalhos publicados, desde que fique explicitado o reconhecimento de sua autoria e a publicação inicial nesta revista. 